\title{
How well do critical care audit and feedback interventions adhere to best practice? Development and application of the REFLECT-52 evaluation tool
}

Madison Foster ${ }^{1,2}$, Justin Presseau ${ }^{1,2,3}$, Eyal Podolsky ${ }^{1}$, Lauralyn Mclntyre ${ }^{1,2,4}$, Maria Papoulias ${ }^{2}$ and Jamie C. Brehaut ${ }^{1,2^{*}}$ (D)

\begin{abstract}
Background: Healthcare Audit and Feedback (A\&F) interventions have been shown to be an effective means of changing healthcare professional behavior, but work is required to optimize them, as evidence suggests that A\&F interventions are not improving over time. Recent published guidance has suggested an initial set of best practices that may help to increase intervention effectiveness, which focus on the "Nature of the desired action," "Nature of the data available for feedback," "Feedback display," and "Delivering the feedback intervention." We aimed to develop a generalizable evaluation tool that can be used to assess whether A\&F interventions conform to these suggestions for best practice and conducted initial testing of the tool through application to a sample of critical care A\&F interventions.

Methods: We used a consensus-based approach to develop an evaluation tool from published guidance and subsequently applied the tool to conduct a secondary analysis of A\&F interventions. To start, the 15 suggestions for improved feedback interventions published by Brehaut et al. were deconstructed into rateable items. Items were developed through iterative consensus meetings among researchers. These items were then piloted on 12 A\&F studies (two reviewers met for consensus each time after independently applying the tool to four A\&F intervention studies). After each consensus meeting, items were modified to improve clarity and specificity, and to help increase the reliability between coders. We then assessed the conformity to best practices of 17 critical care A\&F interventions, sourced from a systematic review of A\&F interventions on provider ordering of laboratory tests and transfusions in the critical care setting. Data for each criteria item was extracted by one coder and confirmed by a second; results were then aggregated and presented graphically or in a table and described narratively.
\end{abstract}

\footnotetext{
* Correspondence: jbrehaut@ohri.ca

${ }^{1}$ School of Epidemiology and Public Health, University of Ottawa, 451 Smyth Road, Ottawa, ON K1H 8M5, Canada

${ }^{2}$ Ottawa Hospital Research Institute, Clinical Epidemiology Program, The

Ottawa Hospital, General Campus, 501 Smyth Road, Centre for Practice

Changing Research, Box 201B, Ottawa, ON K1H 8L6, Canada

Full list of author information is available at the end of the article
}

(c) The Author(s). 2021 Open Access This article is licensed under a Creative Commons Attribution 4.0 International License, which permits use, sharing, adaptation, distribution and reproduction in any medium or format, as long as you give appropriate credit to the original author(s) and the source, provide a link to the Creative Commons licence, and indicate if changes were made. The images or other third party material in this article are included in the article's Creative Commons licence, unless indicated otherwise in a credit line to the material. If material is not included in the article's Creative Commons licence and your intended use is not permitted by statutory regulation or exceeds the permitted use, you will need to obtain permission directly from the copyright holder. To view a copy of this licence, visit http://creativecommons.org/licenses/by/4.0/. The Creative Commons Public Domain Dedication waiver (http://creativecommons.org/publicdomain/zero/1.0/) applies to the data made available in this article, unless otherwise stated in a credit line to the data. 
Results: In total, 52 criteria items were developed (38 ratable items and 14 descriptive items). Eight studies targeted lab test ordering behaviors, and 10 studies targeted blood transfusion ordering. Items focused on specifying the "Nature of the Desired Action" were adhered to most commonly_feedback was often presented in the context of an external priority (13/17), showed or described a discrepancy in performance (14/17), and in all cases it was reasonable for the recipients to be responsible for the change in behavior (17/ 17). Items focused on the "Nature of the Data Available for Feedback" were adhered to less often - only some interventions provided individual (5/17) or patient-level data (5/17), and few included aspirational comparators (2/17), or justifications for specificity of feedback (4/17), choice of comparator (0/9) or the interval between reports (3/13). Items focused on the "Nature of the Feedback Display" were reported poorly-just under half of interventions reported providing feedback in more than one way (8/17) and interventions rarely included pilot-testing of the feedback (1/17 unclear) or presentation of a visual display and summary message in close proximity of each other (1/13). Items focused on "Delivering the Feedback Intervention" were also poorly reported-feedback rarely reported use of barrier/enabler assessments (0/17), involved target members in the development of the feedback (0/17), or involved explicit design to be received and discussed in a social context (3/17); however, most interventions clearly indicated who was providing the feedback (11/17), involved a facilitator (8/12) or involved engaging in self-assessment around the target behavior prior to receipt of feedback $(12 / 17)$.

Conclusions: Many of the theory-informed best practice items were not consistently applied in critical care and can suggest clear ways to improve interventions. Standardized reporting of detailed intervention descriptions and feedback templates may also help to further advance research in this field. The 52-item tool can serve as a basis for reliably assessing concordance with best practice guidance in existing A\&F interventions trialed in other healthcare settings, and could be used to inform future A\&F intervention development.

Trial registration: Not applicable.

Keywords: Audit, Feedback, A\&F, Evaluation tool, Critical care

\section{Contributions to the literature}

- A recent publication provided several suggestions for best practice in the development, design, and delivery of Audit and Feedback (A\&F) interventions; however, the extent of their use in existing interventions is unclear.

- We developed a tool to enable assessment of concordance of A\&F interventions with best practice recommendations and tested the tool using a sample of A\&F interventions delivered in critical care to improve test and transfusion ordering.

- There is considerable room for improving in the reporting and application of these suggestions for best practice in critical care.

- This tool can be used as a guide for evaluating and designing A\&F interventions that adhere to current best practice guidance.

\section{Background}

Audit and feedback (A\&F) (i.e., summarizing provider behavior and feeding the data back to them as a means to spur practice change) is a popular class of healthcare professional behavior change interventions [1]. Despite clear evidence that $A \& F$ is generally effective in improving care, effect sizes across trials of A\&F interventions range from relatively large $(25 \%$ of studies showed a $16 \%$ improvement or better) to null or even negative effects [1]. This variation has important implications. In some cases, it is possible for A\&F to reduce the quality of care; if A\&F is not optimally delivered, providers' performance (and the care received by patients) may be negatively impacted, and resources wasted. Finding ways to optimize A\&F in healthcare is a clear priority [1-3].

Recent guidance summarized suggestions for optimizing A\&F, compiling lessons from interviews with experts in A\&F theory and practical team experience, to produce 15 theory-informed suggestions for high quality A\&F interventions (Table 1) [4]. These suggestions focus on easily modifiable elements of A\&F proposed to improve effectiveness of these interventions to improve behavior change, including the "Nature of the desired action," "Nature of the data available for feedback," "Feedback display," and "Delivering the feedback intervention." While these suggestions appear to be helping in the development of new A\&F interventions [5], they are broadly described and the extent to which published A\&F intervention studies already adhere to them remains unclear. A tool to enable detailed assessment of concordance with these suggestions is needed to enable evidence to accrue on which aspects 
Table 1 Evaluation tool criteria items organized by Brehaut and colleagues' 15 suggestions for improved audit and feedback interventions [4]

\begin{tabular}{ll}
\hline $\mathbf{1 5}$ Suggestions & Criteria Items \\
\hline Nature of the desired action & \\
$\begin{array}{ll}\text { 1. Recommend actions that are } \\
\text { consistent with established goals and } \\
\text { priorities }\end{array}$ & $\begin{array}{l}1.1 \text { Is there any indication that the recipients set an } \\
\text { target/threshold)? } \\
\end{array}$ \\
& $\begin{array}{l}1.2 \text { Was feedback presented in the context of an } \\
\text { external, explicit priority? }\end{array}$
\end{tabular}

2. Recommend actions that can improve and are under the recipient's control

3. Recommend specific actions

\section{Nature of the data available for feedback}

4. Provide multiple instances of feedback

5. Provide feedback as soon as possible and at a frequency informed by the number of new patient cases
2.1 Was feedback on performance provided to allow current performance to be compared against previous performance?

2.2 Does the feedback (or the description of the feedback) describe or show a discrepancy between recipient performance and the goal/ benchmark target/comparator?

2.3 Is it reasonable that the feedback recipient can be responsible for the change in behavior?

2.4 Does the feedback provide data on behaviors, outcomes, or both?

3.1 Did the feedback intervention incorporate suggested corrective actions to support plans for problem solving? For example: action plans, coping strategies, a menu of options, etc.

4.1 Was feedback (for a given behavior) provided more than once?

4.2 Did recipients continue to receive feedback on their performance after the study was completed?

5.1 What is the average age of the data (i.e. interval between the clinical encounter and delivery of the feedback)?

5.2 If feedback was provided more than once, what was the time interval between the receipt of feedback reports?

5.3 Do the authors of the study provide a justification for the interval between feedback reports?

5.4 Was the justification for the interval between feedback reports related to the number of patient cases?

6. Provide individual rather than general data performance?
1.3 If yes, at what level was the priority set?

1.4 Does the feedback directly address one or more of the goals or priorities?

Response Scale

Yes/ No/ Not Reported/ Unclear

Yes/ No/ Not Reported/ Unclear

National/Federal, Provincial/State, Municipal, Institutional, Departmental, Individual-healthcare providers, Individual- researchers, Other (Please specify), Not Reported, Unclear, N/A

Yes/ No/ Not Reported/ Unclear/ N/A

Yes/ No/ Not Reported/ Unclear

Yes/ No/ Not Reported/ Unclear

Yes/ No/ Not Reported/ Unclear

For each, answer:

Yes/ No/ Not Reported/ Unclear

Yes/ No/ Not Reported/ Unclear

Yes/ No/ Not Reported/ Unclear/ Other

Yes/ No/ Not Reported/ Unclear

Describe (i.e. Days, Weeks, Months, Years, Not Reported, Unclear)

Describe (i.e. Hours, Days, Weeks, Months, Years, Variable, Not Reported, Unclear, N/A)

Yes/ No/ Unclear/ N/A

Yes/ No/ Unclear/ N/A

Yes/ No/ Not Reported/ Unclear

6.2 Was feedback about the performance of a group Yes/ No/ Not Reported/ Unclear of which the recipient is a member?

6.3 What is the level of the group?

6.4 Did feedback include patient- level data for the recipient's own patients?

6.5 Did feedback include aggregated patient data involving recipient's own patients?
Describe: Unit, Department, Practice, Hospital, Region, Province, Other (please specify), Not Reported, N/A

Yes/ No/ Not Reported/ Unclear

Yes/ No/ Not Reported/ Unclear 
Table 1 Evaluation tool criteria items organized by Brehaut and colleagues' 15 suggestions for improved audit and feedback interventions [4] (Continued)

\begin{tabular}{ll}
\hline $\mathbf{1 5}$ Suggestions & Criteria Items \\
\hline & 6.6 Do the authors give a justification for the \\
specificity of the feedback (or a reason for the level \\
of data presented)?
\end{tabular}

\section{Response Scale}

Yes/ No/ Unclear

Yes/ No/ Not Reported/ Unclear

1, 2, 3, More than 3, None, Not Reported, Unclear, Other (describe as needed)

Own previous performance, Other's performance, Benchmark/ Standardized Guideline/Target, Other, Not Reported, Unclear

Yes/ No/ Not Reported/ Unclear/ Other

Yes/ No/ Unclear/ N/A

\section{Feedback display}

8. Closely link the visual display and summary message

8.1 Are the visual display and the summary message presented in visual proximity of each other?
9. Provide feedback in more than one way

10. Minimize extraneous cognitive load for feedback recipients

9.1 Was feedback provided in more than one way?

9.2 Does the feedback intervention include: 1) Verbal interaction; 2) Text; 3) Numerical information; 4) Graphs or tables; 5) A summary message; 6) Other important elements (please specify)?

10.1 Was the feedback intervention pilot-tested?

10.2 How long is the feedback report?

10.3 How many behaviors does the feedback address?

10.4 How many clinical variables were fed back to the recipients?

10.5 How many graphs or tables are used?

10.6 Did the feedback include any graphical elements that lend themselves to misinterpretation? (Ex. Pie charts, 3D graphs, etc.)

\section{Delivering the feedback intervention}

11. Address barriers to feedback use

11.1 Were potential drivers and barriers to recipients engaging with the feedback component of the intervention assessed?

11.2 Was the assessment informed by theory?

11.3 Was there an assessment of whether the recipients engaged with the feedback?

11.4 Was the assessment informed by theory?

12. Provide short, actionable messages 12.1 Are the summary messages actionable (or followed by optional detail described as actionable)?

12.2 Is there additional, more detailed feedback provided alongside the summary message?

13. Address credibility of the information
13.1 Does the feedback (or the description of the feedback) indicate who is providing the feedback data?

13.2 Does the feedback intervention indicate the source of comparators?

13.3 Was the feedback intervention delivered by a supervisor or close colleague?
Yes/ No/ Not Reported/ Unclear/ N/A

Yes/ No/ Not Reported/ Unclear

Provide an answer for each item: Yes/ No/ Not Reported/ Unclear

Yes (with target population)/ Yes (with non-target population)/ No/ Not Reported, Unclear

Describe

1, 2, 3, 4, 5-9, more than 9, Not Reported, Unclear, Other (describe as needed), N/A

Describe/ Not Reported/ Unclear

Describe/ Not Reported/ Unclear

Yes/ No/ Not Reported/ Unclear/ N/A

Yes/ No/ Not Reported/ Unclear

Yes/ No/ Not Reported/ Unclear/ N/A

Yes/ No/ Not Reported/ Unclear/ Other

Yes/ No/ Not Reported/ Unclear/ N/A

Yes/ No/ Not Reported/ Unclear/ N/A

Yes/ No/ Not Reported/ Unclear

Yes/ No/ Not Reported/ Unclear

Yes/ No/ Not Reported/ Unclear/ Other

Yes/ No/ Not Reported/ Unclear 
Table 1 Evaluation tool criteria items organized by Brehaut and colleagues' 15 suggestions for improved audit and feedback interventions [4] (Continued)

\begin{tabular}{|c|c|c|}
\hline 15 Suggestions & Criteria Items & Response Scale \\
\hline & $\begin{array}{l}\text { 13.4 Was the feedback intervention supported by a } \\
\text { relevant professional organization? }\end{array}$ & Yes/ No/ Not Reported/ Unclear \\
\hline $\begin{array}{l}\text { 14. Prevent defensive reactions to } \\
\text { feedback }\end{array}$ & $\begin{array}{l}14.1 \text { Did the feedback intervention include } \\
\text { reassurance that the intervention would not trigger } \\
\text { punitive measures? }\end{array}$ & Yes/ No/ Not Reported/ Unclear/ Other \\
\hline \multirow[t]{6}{*}{$\begin{array}{l}\text { 15. Construct feedback through social } \\
\text { interaction }\end{array}$} & $\begin{array}{l}\text { 15.1 Did development of the feedback intervention } \\
\text { involve members of the target group? }\end{array}$ & Yes/ No/ Not Reported/ Unclear \\
\hline & $\begin{array}{l}15.2 \text { Was the feedback explicitly designed to be } \\
\text { received and discussed in a social context? }\end{array}$ & Yes/ No/ Not Reported/ Unclear/ Other \\
\hline & $\begin{array}{l}15.3 \text { If feedback was provided more than once, how } \\
\text { often was feedback received and discussed in a } \\
\text { social context? }\end{array}$ & $\begin{array}{l}\text { Every time feedback was provided, Only once, } \\
\text { Variably, Not Reported, Unclear, Other (please specify), } \\
\text { N/A }\end{array}$ \\
\hline & $\begin{array}{l}15.4 \text { If feedback was received and discussed in a } \\
\text { social context, was the feedback discussion facilitated } \\
\text { by a facilitator? }\end{array}$ & Yes/ No/ Not Reported/ Unclear/ N/A \\
\hline & $\begin{array}{l}15.5 \text { Did the feedback intervention involve engaging } \\
\text { in self- assessment around target behaviors prior to } \\
\text { receiving feedback? }\end{array}$ & Yes/ No/ Not Reported/ Unclear \\
\hline & $\begin{array}{l}\text { 15.6 Did the investigators actively seek feedback } \\
\text { from the recipients on the feedback? }\end{array}$ & Yes/ No/ Not Reported/ Unclear \\
\hline
\end{tabular}

of A\&F best practice are being used and which could be optimized in a given literature and setting.

A\&F may be a particularly well-suited intervention to change behavior in complex environments such as critical care. In this setting, critically ill patients are rigorously monitored in intensive care units (ICUs) and treated by interdisciplinary teams of healthcare providers, composed of individuals from various professional backgrounds [6-8]. Due to the severity of patient illness, the ICU is a fast-paced and high pressure environment $[9,10]$. This creates a stressful workplace, not only emotionally (due to the requirement to make difficult decisions quickly), but also as a result of physical and professional factors [10]. Poor lighting, alarms with low sensitivity, and similar sounds for different warnings, poorly placed equipment, and a multitude of cords and tubes have been cited as physical factors adding to the stressful environment of the ICU $[6,10]$. ICUs also produce a large amount of patient data (i.e., vital signs and laboratory data), which can be difficult for individual providers to process $[6,11]$.

Many behaviors within critical care (test ordering, transfusion ordering) can become routine [12] such that those ordering may not be as aware of the frequency with which orders are being made. This may in turn lead to potentially unnecessary blood draws, putting patients at risk for anemia, and increased cost of care and resources to collect, run, and interpret tests [13-18], or potentially unnecessary use of precious blood products [18-25]. Providing performance data on routinized behaviors may help to highlight the frequency with which these orders are placed and flag them for improvement. Feedback can be provided to both individuals and groups in a variety of ways, which may be useful in addressing the team-based and multidisciplinary $[7,10]$ nature of the critical care setting. Moreover, data on common practices like laboratory test ordering in this setting are readily available to allow for auditing and production of feedback reports.

We recently conducted a systematic review [26] of the use and effectiveness of A\&F interventions in critical care. In the current study, we sought to assess the extent to which these identified A\&F intervention studies included Brehaut et al.'s 15 suggestions [4]. These suggestions were designed to provide general guidance to feedback developers (those who actively design A\&F displays, e.g., information technology developers, researchers, quality improvement professionals) with each suggestion encompassing multiple concepts that can be applied in a variety of different ways. To better assess how existing A\&F interventions may adhere to these suggestions, we aimed to develop an evaluation tool by deconstructing each of the 15 suggestions into unidimensional items that could be reliably rated. Our objectives for this study were to report the development of this evaluation tool, as well as an initial testing of this tool through application to a sample of published A\&F intervention studies in the field of critical care.

\section{Methods}

A consensus-based approach was used to develop the evaluation tool from Brehaut et al.'s suggestions for 
improved A\&F. A secondary analysis of A\&F interventions was also undertaken to apply the tool and assess the extent to which these practices are observed in the critical care literature. Given the descriptive nature of the evaluation tool, and our narrative approach to reporting the development and application of the tool, results were reported as per the consolidated criteria for reporting qualitative studies (COREQ) checklist (Additional File 1) [27].

\section{Development of items and response categories}

Items were developed by the research team (JCB, JP, MF, MP). First, suggestions encompassing more than one distinct concept were split into items that addressed a single concept. Next, items were worded to facilitate reliable rating of $A \& F$ interventions using an iterative process, whereby items were discussed until consensus was reached that the items adequately represented the key components of each suggestion. Items were then deduplicated, and any items that were judged likely to be difficult to assess from published articles or feedback templates were removed.

Response categories, item-specific anchors, and examples of adherence to increase inter-rater reliability were also developed as part of the coding manual. The response categories (Yes/No/Unclear/Not Applicable) were chosen for most items to facilitate quantitative summaries ("ratable" items, wherein adherence could be determined); the remaining "descriptive" items used a combination of descriptive or numerical response categories, to provide further details about the A\&F intervention component (e.g., number of comparators, type of comparators).

\section{Evaluation tool piloting}

A sample of A\&F intervention studies were selected from the 2012 A\&F Cochrane Review [1] (from outside of the critical care setting, and not necessarily focused on test or transfusion ordering) to pilot the evaluation criteria and assess inter-rater reliability. Each sample, containing four A\&F interventions, was independently rated with the pilot criteria by two raters (MF and MP). Consensus meetings were held after application to each sample, to compare data extraction results between raters, discuss discrepancies, and modify the wording of items as necessary to improve their clarity, rateability, and mutual exclusivity. The descriptive anchors and examples were also updated and added to as needed. Disagreements between raters were resolved by a third individual (JCB). Twelve different A\&F intervention studies were rated in total. Inter-rater reliability was measured by tabulating agreement scores and calculating Cohen's Kappa in Microsoft Excel, for the ratable items (items which used "Yes/No/Unclear/Not Applicable" response categories) (Additional File 2) [28]. The pilot study concluded once all ambiguities had been clarified and the research team agreed that the criteria items comprehensively covered all 15 suggestions [4].

\section{Identification and collection of study materials for application of the evaluation tool}

Studies evaluating A\&F interventions that were targeted to improve laboratory test and transfusion (red blood cell, platelet, plasma, cryoprecipitate) ordering in a critical care setting were previously identified through a systematic review [26]. The review summarized the current evidence on the use of A\&F for quality improvement of lab test and transfusion ordering decisions in critical care. Sixteen studies (17 publications) were identified; six of which aimed to improve lab test ordering [29-35], eight of which aimed to improve blood transfusion ordering [36-43], and two of which assessed both types of orders $[44,45]$. Corresponding authors from all 17 publications were contacted by email to request a template of the feedback form used and any other pertinent details about the intervention.

\section{Application of the evaluation tool Data extraction}

After development and pilot testing, we used the evaluation tool to assess the sample of 17 A\&F interventions (from 16 studies) [29-45] identified by our previous systematic review [26]. One reviewer (MF) extracted data both from published reports and, when provided by authors, the sample feedback forms. Data was collected using a data extraction form in Microsoft Excel; data extraction was then confirmed by a second reviewer (EP). Disagreements were resolved through consensus, or when an agreement could not be reached, through input from a third reviewer (JCB).

\section{Analysis}

Descriptive statistics for the criteria items (the number of A\&F interventions coded to each response category) were computed and tabulated manually in Microsoft Excel. Results are described in the text and presented graphically (rateable items) or in a table (descriptive items). Gaps in the current literature (items with low adherence) were also identified and discussed narratively.

\section{Ethics}

This study was approved by the Ottawa Health Science Network Research Ethics Board (OHSN-REB; Protocol ID: 20160951-01H). 


\section{Results}

\section{Development and piloting of the evaluation tool}

Through iterative team discussions, the 15 suggestions were deconstructed into 39 ratable items and 12 descriptive items. After the pilot, a Cohen's Kappa of 0.58 was computed for the ratable items. This Kappa score represents "moderate agreement" as per Landis and Koch, but is below Krippendorff's cut-off "suggesting that conclusions should be discounted" [28]. This relatively low agreement score was partially driven by discrepancies in determining whether the item was not present ("no") versus "not applicable" or "unclear." We therefore proceeded to use our primary approach of establishing consensus for each study in the final assessment. Through the pilot consensus meetings, it was determined that two ratable criteria items should be removed (deemed redundant or too difficult to assess), two new items were developed (one ratable and one descriptive), and one descriptive item was re-worded to a ratable item. This resulted in a total of 39 ratable and 12 descriptive items for the application of the evaluation tool. The response scale for the descriptive item "Does the feedback intervention include: (a) verbal interaction, (b) text, (c) numerical information, (d) graphs or tables, (e) a summary message, (f) other important elements" was also adjusted such that reviewers were to answer "Yes/No/Unclear/ Not Applicable" for each sub-category. "Not reported" was also later added as a response category for all items in the final assessment to differentiate between cases where the answer could not be determined due to lack of reporting or lack of access to the feedback form, as compared to cases where the answer was a clear "No" or "Unclear" (e.g., ambiguous wording or statement).

Post hoc, it was determined that two ratable items ("Does the feedback include group performance data for which the recipient is a member?" and "Does feedback include aggregated patient data involving the recipient's own patients?") were better suited as descriptive items, as adherence to the overall suggestion could not be directly determined. An additional ratable item ("Was feedback provided in more than one way?") was also added ad hoc, to summarize findings from the descriptive item "Does the feedback intervention include: (a) verbal interaction, (b) text, (c) numerical information, (d) graphs or tables, (e) a summary message, ( $f$ ) other important elements." In the final application of the tool, there were thus 38 ratable items and 14 descriptive items.

Table 1 describes the final 52 criteria items deconstructed and operationalized from the 15 suggestions (Nature of the Desired Action = 9 items; Nature of the Data Available for Feedback $=17$ items; Feedback Display $=9$ items; Delivering the Feedback Intervention = 17 items). The full evaluation tool, including anchors, is described in Additional File 3.

\section{Identification of studies and collection of study materials} for application of the evaluation tool

Sixteen studies (17 publications) describing 17 A\&F interventions (one study compared two different types of feedback) were identified by our systematic review [26]. Additional File 4 provides a flow diagram of the study selection. One study presented an example of the feedback form within the publication, while another presented a portion of the feedback form (the feedback data graph) within the publication. Four authors were able to provide an example of the feedback form utilized in the study as well as additional pertinent details (e.g., whether verbal feedback was provided), and two authors responded but were unable to provide further details (response rate $=6 / 17$ articles $(35 \%)$. As one of the authors provided examples for the study with two types of A\&F interventions, we received feedback forms for five of the 17 interventions (29\%); including the two examples provided within the publications, we had access to forms for seven of the 17 interventions (41\%).

\section{Sample of A\&F interventions for application of the evaluation tool}

Table 2 (reproduced from the systematic review [26]) describes the sample of critical care A\&F intervention studies assessed. The review [26] identified a heterogeneous sample of multicomponent quality improvement interventions involving A\&F; eight studies aimed to improve lab test ordering [29-35, 44, 45] and ten studies aimed to improve transfusion ordering [36-45]; two of these studies aimed to improve both practices [44, 45], and one compared two types of A\&F interventions [39]. Fifteen of the 17 interventions incorporated one or more additional components, such as education, guidelines, opinion leaders, financial incentives, checklists, or administrative interventions. The plurality of interventions reported providing feedback more than once (53\%), in only a written format (41\%), with data aggregated at the group level only (41\%). Feedback was most often provided to multiple groups of healthcare providers (29\%) or physicians only (24\%). Heterogeneity of the outcomes precluded meta-analysis; however, overall the majority of interventions reported statistically significant behavior changes in the hypothesized direction. Most studies were judged to be of high risk of bias, due to use of an uncontrolled before/after design, lack of time series analysis, and poor reporting of intervention details, hindering replication.

\section{Application of the evaluation tool}

Figures 1, 2, 3, and 4 describe consistency with the 38 ratable items and 3 of the 14 descriptive items (those with a "Yes/No/Not Reported/Unclear/Not Applicable" scale). To enhance clarity, the remaining 11 descriptive 
Table 2 Summary of study characteristics ${ }^{a, d}$

\begin{tabular}{|c|c|c|c|}
\hline Clinical behavior targeted & $\begin{array}{l}\text { Number (\%) of studies } \\
(n=16)\end{array}$ & Country & $\begin{array}{l}\text { Number (\%) of studies } \\
(n=16)\end{array}$ \\
\hline Laboratory test ordering & $8(50.0 \%)$ & USA & $9(56.3 \%)$ \\
\hline Multiple, miscellaneous or unspecified tests & $3(18.8 \%)$ & Canada & $2(12.5 \%)$ \\
\hline$A B G$ & $2(6.3 \%)$ & Finland & $1(6.3 \%)$ \\
\hline Lactate and blood cultures & $1(6.3 \%)$ & Germany & $1(6.3 \%)$ \\
\hline Superficial cultures & $1(6.3 \%)$ & Israel & $1(6.3 \%)$ \\
\hline Blood work & $1(6.3 \%)$ & The Netherlands & $1(6.3 \%)$ \\
\hline Transfusion ordering & $10(62.5 \%)$ & Switzerland & $1(6.3 \%)$ \\
\hline RBCs & $6(37.5 \%)$ & Number of sites & \\
\hline FP/FFP & $3(18.8 \%)$ & Single centre, single ICU study & $9(56.3 \%)$ \\
\hline All (RBC, FFP, platelets, cryoprecipitate) & $1(6.3 \%)$ & Single centre, multi-ICU study & $4(25.0 \%)$ \\
\hline Study design & & Multicentre study & $2(12.5 \%)$ \\
\hline Uncontrolled before after & $13(81.3 \%)$ & Single centre, \# ICUs unclear & $1(6.3 \%)$ \\
\hline Cluster randomized controlled trial & $1(6.3 \%)$ & Hospital type & \\
\hline Controlled clinical trial ${ }^{b}$ & $1(6.3 \%)$ & Teaching & $11(68.8 \%)$ \\
\hline Controlled before after & $1(6.3 \%)$ & Not Reported & $3(18.8 \%)$ \\
\hline Data collection & & Other: Veteran's Administration Medical Centre & $1(6.3 \%)$ \\
\hline Prospective & $5(31.3 \%)$ & ICU type & \\
\hline Retrospective & $4(25.0 \%)$ & Surgical & $2(12.5 \%)$ \\
\hline Mixed & $3(18.8 \%)$ & Neonatal & $2(12.5 \%)$ \\
\hline Unclear & $4(25.0 \%)$ & Cardiac Surgery & $3(18.8 \%)$ \\
\hline Funding & & Neurosurgical & $1(6.3 \%)$ \\
\hline Not reported & $8(50.0 \%)$ & Medical & $1(6.3 \%)$ \\
\hline Government grant & $4(25.0 \%)$ & Mixed Patient Population & $2(12.5 \%)$ \\
\hline Institutional ${ }^{\complement}$ and non-profit grants & $2(12.5 \%)$ & Multiple Types of ICUs & $3(18.8 \%)$ \\
\hline Institutional $^{\mathrm{C}}$ & $1(6.3 \%)$ & Not Specified & $2(12.5 \%)$ \\
\hline No Funding & $1(6.3 \%)$ & & \\
\hline
\end{tabular}

$A B G$ arterial blood gas, $C P$ cryoprecipitate, $F P$ frozen plasma, FFP fresh frozen plasma, $I C U$ intensive care unit, $R B C$ red blood cell

${ }^{a}$ Proportions were calculated for the 16 studies, rather than the 17 publications. Totals may be slightly greater or less than $100 \%$ due to rounding

${ }^{\mathrm{b}}$ The control group was another type of A\&F

'Institution' refers to both hospitals and academic institutions

${ }^{\mathrm{d}}$ Reprinted from Implementation Science [26] (Open Access)

items (e.g., Level at which the priority was set) have been described in Additional File 5.

\section{Nature of the desired action}

Figure 1 describes adherence to the eight ratable items operationalized from the three "Nature of the Feedback's Desired Action" suggestions. Descriptions about presenting feedback interventions in the context of external priorities were generally adhered to (13/17), and the feedback generally addressed these priorities (13/17), but information about whether the feedback involved setting of internal goals by recipients was rarely made clear $(16 / 17$ rated as not reported; $1 / 17$ unclear). For all interventions (17/17), it was found to be reasonable that the feedback recipient could be responsible for the change in behavior, and most interventions (14/
17) showed or described a discrepancy between recipient performance and a goal, benchmark, target or comparator. However, whether the feedback allowed for comparison of current performance against previous performance was adhered to variably (6/17), and few interventions (3/17) explicitly incorporated suggested corrective actions to support plans for problem solving (e.g., action plan, coping strategy, menu of options, etc.).

\section{Nature of the data available for feedback}

Figure 2 describes the ten ratable items and two of the descriptive items derived from the four "Nature of the Data Available for Feedback" suggestions. Though the majority of interventions reported providing feedback more than once (10/17; other (unclear/variable): 3/17), 


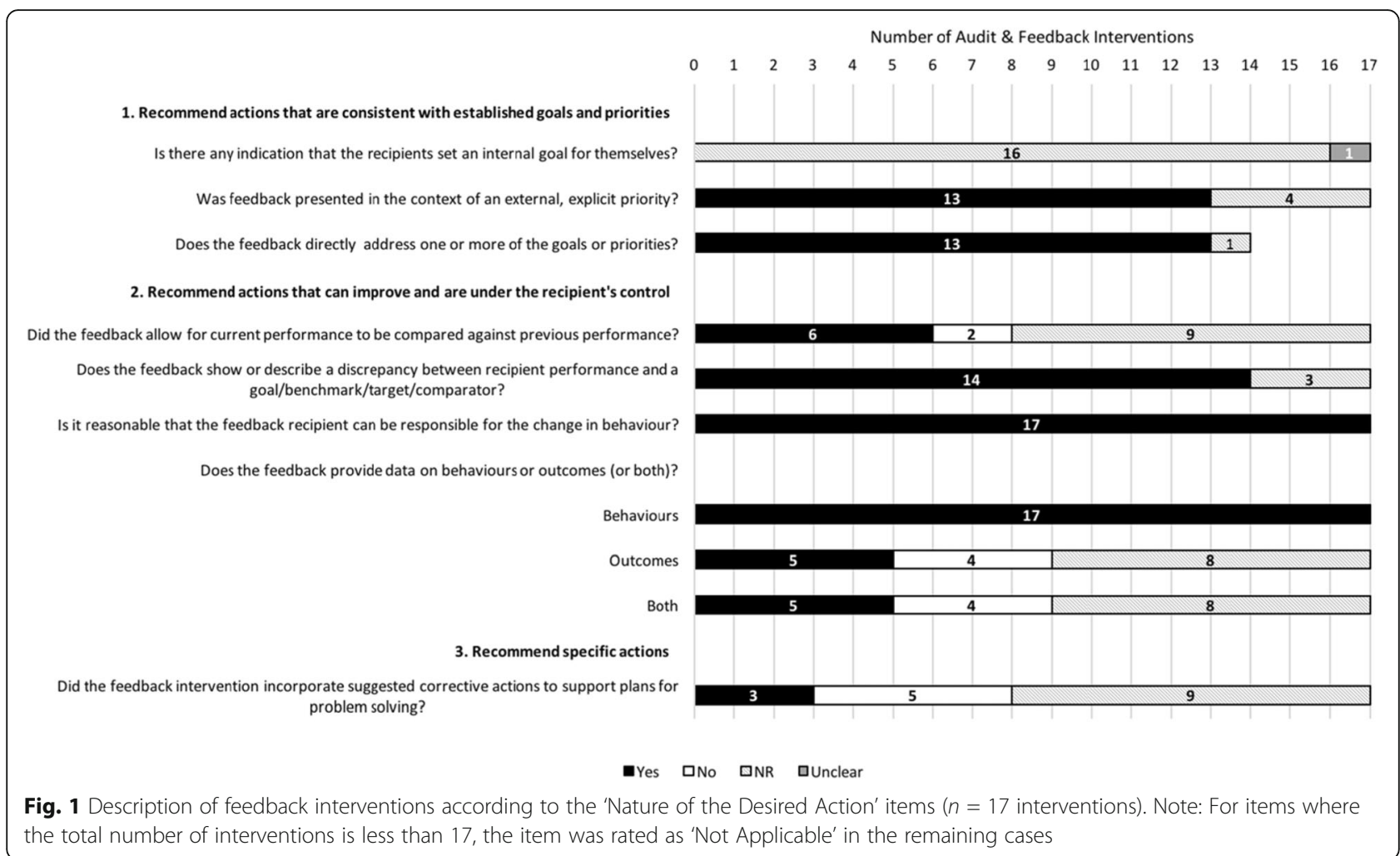

few reported continuing to provide feedback after the study (3/17). Only some of the interventions adhered to including data about the individual's own performance $(5 / 17)$ and patient-level data (5/17) (most reported including group level performance data (12/17) and aggregated patient data (11/17)). About half of interventions reported adherence to providing a comparator (9/17); however, few reported including an aspirational comparator $(2 / 17$; and other $(100 \%$ compliance implied but not made explicit): $2 / 17$ ). Justifications were rarely provided for specificity of the feedback (4/17), choice of comparator(s) (0/9), or the interval between feedback reports $(3 / 13$; though $2 / 3$ justifications were related to the number of patient cases).

\section{Feedback display}

Figure 3 describes the sample's adherence to the four ratable items (and one of the description items) operationalized from the three "Feedback Display" suggestions. Just under half of interventions $(8 / 17)$ adhered to providing feedback in more than one way; interventions clearly included a verbal feedback component in eight cases, numerical information in seven, graphs or tables in six, text in five, a summary message in three, and other (color coding) in two. However, none of the interventions reported pilot-testing of the feedback $(0 / 17$; one intervention unclear). Only one intervention adhered to presenting a visual display and summary message in visual proximity of each other, though in the majority of cases, not enough information was reported to determine this $(12 / 13$ not reported; 4/17 not applicable). Of the five ratable cases, two interventions were found to include graphical elements that lend themselves to misinterpretation.

\section{Delivering the feedback intervention}

Figure 4 describes the sample's adherence to the 16 ratable items operationalized from the five "Delivery of the Feedback" suggestions. Interventions rarely reported conducting barrier/enabler assessments $(0 / 17)$ or assessments of whether recipients engaged with the feedback (2/17; though 6/17 were rated as "other" [no or not reported, but verbal feedback component]). No interventions reported use of theory to inform such assessments (17/17 not applicable and 0/2, respectively). None of the interventions reported involving members of the target group in the development of the feedback, and none were found to include "actionable" summary messages $(0 / 14$, though not reported in $11 / 14)$. Few interventions were explicitly designed to be received and discussed in a social context (3/17), though 5/17 were rated as "other" (no explicit statement reported, but feedback was provided in a social context). Furthermore, few actively sought feedback from the recipients $(2 / 17)$ or provided additional more detailed feedback alongside the summary message (2/17, though not reported in $12 / 17)$. 


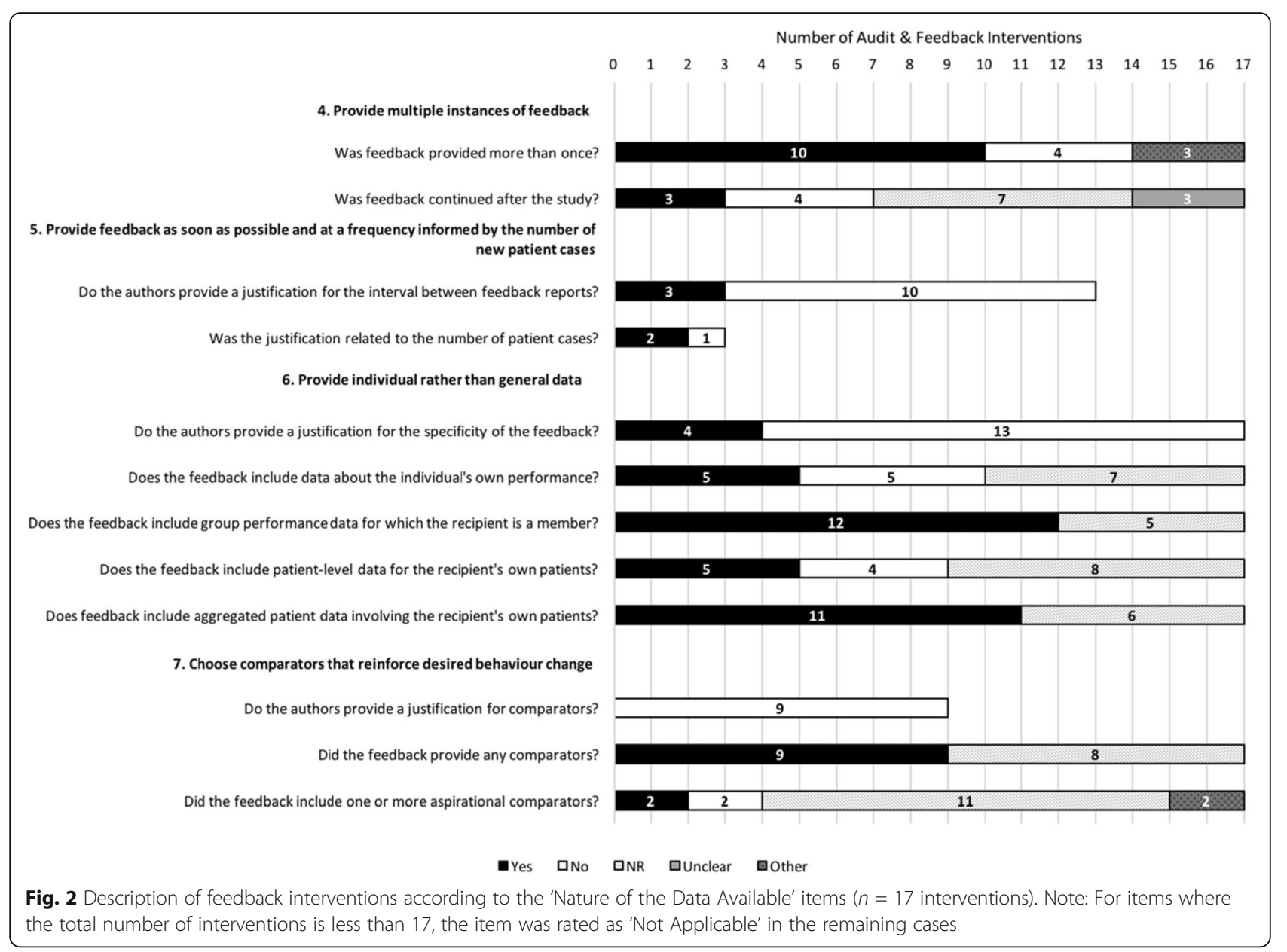

However, most interventions did adhere to clearly indicating who was providing the feedback (e.g., provided verbally or through email) (11/17), and most including a comparator clearly indicated the source of the comparator(s) (6/9; and 1/9 "other" [yes, no form but would be obvious; overall institution versus own specific ward]). Although no interventions were found to be supported by a relevant organization or explicitly reported providing reassurance that the intervention would not trigger punitive measures, some were delivered by a supervisor or close colleague (6/17) or reported other methods aiming to reduce defensive reactions (6/17). Most interventions also involved engaging in self-assessment around the target behavior(s) prior to receiving feedback (e.g., an educational session) (12/17), and of those that involved receiving and discussing feedback in a social context, most were facilitated by a facilitator (8/12).

\section{Discussion}

The development of our evaluation tool represents an important step forward in improving A\&F interventions. A total of 52 criteria items (38 ratable and 14 descriptive) were operationalized from the 15 suggestions for best practice [4]. To address the uncertainty surrounding the specifics of how best to apply each suggestion, we developed a comprehensive set of items which aimed to capture the various ways in which these suggestions could be employed. This tool allows for assessment of the extent to which $A \& F$ interventions adhere to recent guidance for best practice [4]. Future studies may apply this tool to assess how A\&F interventions in various settings adhere to these items, as well as whether adoption of these practices improves over time. Moreover, our tool may be used prospectively for the development of A\&F interventions, to test the various hypotheses.

Our work to apply this evaluation tool to a sample of critical care related A\&F interventions shows that most items are not being consistently implemented or reported across the critical care A\&F literature. Of the 38 ratable items, only two were universally applied (Is it reasonable that the feedback recipient can be responsible for the change in behavior? and Does the feedback provide data on behaviors or outcomes (or both)?). This was not particularly surprising as all studies within the sample were published prior to or within the same year as the suggestions for best practice [4], which were 


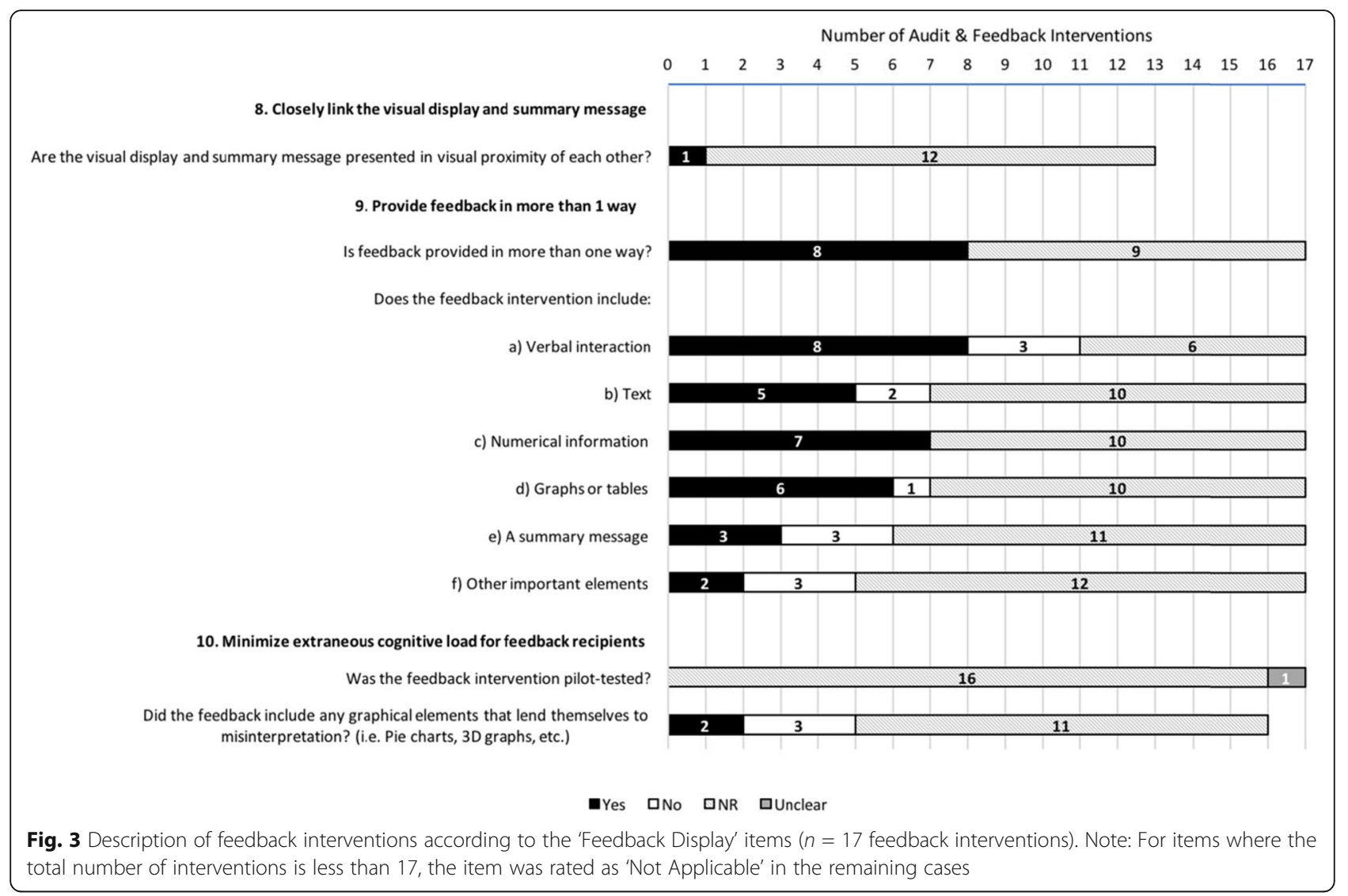

hypothesized to be relatively underutilized elements within the existing A\&F literature. The results from this study suggest there may be considerable room for improvement in the development and delivery of A\&F interventions for laboratory test and transfusion ordering in the critical care setting and point to several theoretical considerations that warrant further study.

We also found that the study details required to assess many items were simply not reported (20/52 items were not reported in the majority of studies). It was especially difficult to assess adherence with the items related to the design and delivery of the feedback, as we were not always able to access an example of the feedback form (had access to 7/17 feedback templates (41\%), one form was partial). Better access to feedback form templates may have allowed for more complete extraction of the details necessary for our assessment. Our findings suggest a standardized method for reporting A\&F intervention details and readier access to feedback form templates may help to move research in this field forward.

\section{Use of theory in A\&F}

There is interest and utility in utilizing theory to improve the design, implementation, and assessment of behavior change interventions, as suggested in the Medical
Research Council's guidance $[46,47]$. A priori predictions of mechanisms of action for complex interventions through consideration of relevant theories can facilitate a better understanding of why an intervention is or is not successful [48-50]. Recent analyses of the A\&F literature (the 140 studies included in the Cochrane systematic review) [48], as well as the more general implementation literature (guideline implementation) [51], however, have revealed low rates of reported theory use. A review assessing the use of theory across Cochrane systematic review A\&F interventions found theory was mentioned in only $14 \%$ of studies, and only $9 \%$ of them referenced theory in terms of A\&F design [48]. Researchers may have difficulty selecting theories for application to their interventions and studies, due to the lack of consensus and, until recently, lack of guidance on how best to choose from numerous theories [52-54]. To synthesize theoretically informed guidance for A\&F developers, Brehaut and colleagues conducted interviews with theory experts and drew from team experience and systematic reviews [4]. Our finding that many of these theoretically informed suggestions are underutilized in the existing critical care A\&F literature is therefore in line with these previous studies. Below we've described several key suggestions for which our sample showed low consistency, to highlight priorities for future research. 


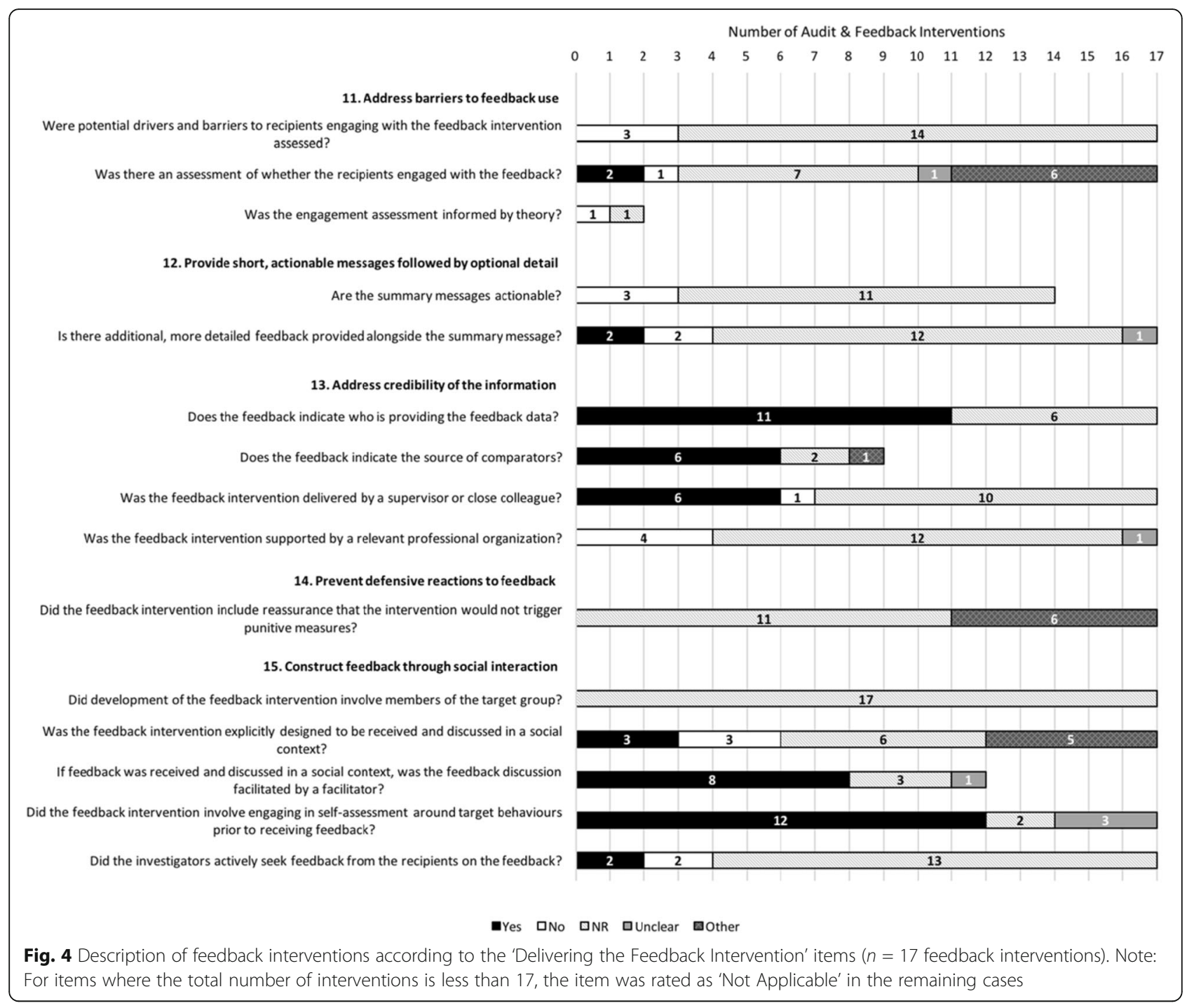

\section{Underutilized suggestions in critical care A\&F}

Counter to Brehaut et al.'s suggestion to "provide multiple instances of feedback" [4], some interventions (4/ 17) only provided feedback once, while others did not clearly report whether feedback was provided more than once or provided feedback variably (e.g., only if an order was placed inappropriately) (3/17). This finding is important because providing feedback more than once allows for a cyclical process whereby the recipient first receives feedback on their behavior (and potentially suggestions on how to improve) [4]. If allowed the chance to change their behavior, upon receiving feedback again, individuals may gauge whether their efforts were successful or not. Without iterative feedback, recipients may not be able to determine their progress on whether their efforts were successful. As it is suggested that individuals are unable to accurately assess their own performance, this is an important part of the feedback loop $[1,4,55]$.
Several A\&F interventions $(7 / 17,41 \%)$ only clearly reported presenting data aggregated at the group level. Brehaut et al.'s recent guidance suggests feedback provide data at the individual level, to dissuade discounting of the data [4]. However, as noted in one study, it may be difficult to "assign" orders to individual healthcare providers if the decision is made by the team [38]. A previous meta-analysis also found a combination of group and individual data to result in a larger effect size than either type alone [56]. It may therefore be of interest to further assess whether providing both individual and group level data is more effective in team-based settings such as the ICU.

While none of the studies reported providing reassurance that the feedback intervention would not result in punitive measures, studies for six of the interventions did report the incorporation of other aspects (e.g., providing both positive and negative feedback, providing group data to avoid singling out individuals, using non- 
punitive wording, etc.) that were consistent with the suggestion to aim to "Prevent defensive reactions to feedback" [4]. This is an important component, as previous qualitative work has identified that providers may have initial defensive reactions to negative feedback $[57,58]$. It is also imperative to note that our criteria item represents only one way of potentially preventing defensive reactions, the effectiveness of which should still be tested. Further work is required to elucidate methods on how best to avoid negative reactions to feedback.

Other areas of poor adherence included the lack of reported use of elements such as piloting of the feedback form, involvement of key stakeholders, barrier and engagement assessments, goal setting, and action and coping plans. Due to a lack of reporting, it is unclear whether low adherence may simply represent a reporting issue, or if these steps are not being taken. If these elements are not being incorporated, it would be valuable to assess whether incorporation of these elements in A\&F studies helps to improve behavior change in the critical care setting. Involving stakeholders in the development process may also help to identify priorities and appropriate modalities through which to provide feedback. Previous qualitative work has found that ICU specialists feel A\&F to be a "fragmented or discontinuous communication," "often not actionable," and have noted that the audit process can "[lack] transparency and credibility" [57]. Engaging stakeholders throughout the development of the feedback may also help to ensure providers feel a part of the process and that the feedback provided is useful and positively received. Further, as laboratory test and transfusion ordering are likely habitual behaviors, use of supports such as action or coping plans may be especially pertinent, because it's hypothesized that these plans can help to form new habits $[12,59]$.

\section{Strengths and limitations}

A limitation of our study is the potential for lack of reporting on key details in the intervention descriptions available to us. As demonstrated by Colquhoun et al., the reporting quality of A\&F intervention details varies [60]. Since the majority of studies in our sample used multiple intervention components, space limits may have especially inhibited reporting of such details. As varied reporting was anticipated, we aimed to counter this limitation by contacting the study authors to obtain further details and request an example of the feedback form used during the study; having access to the feedback form allows for more complete coding. Another limitation of our tool is that without access to feedback examples, a number of the developed criteria items are difficult or not possible to rate (e.g., items relating to the feedback design). An important way to move this literature forward and ensure that $A \& F$ interventions improve is thus to make these documents available. We also note that there are limitations to the development approach taken. Though this work builds on guidance developed through a comprehensive approach (systematic reviews, interviews, team experience), it was still limited to this set of recommendations. Thus, there may still be additional important elements for A\&F not captured. Furthermore, as our sample was limited to the critical care setting, it is also unclear whether our results would have been similar across different patient populations or stakeholder groups. Application of our evaluation tool to different settings, and by external users, will be a valuable area for future study, and important in ensuring generalizability of the tool. Further psychometric testing will also be required in future work to assess construct, content and criterion validity [61]. Due to the variation in reporting of intervention details, limited access to feedback templates, and above mentioned limitations, the current evaluation tool, which we have tentatively named REFLECT-52 (REassessing audit \& Feedback interventions: a tooL for Evaluating Compliance with suggested besT practices), cannot claim to quantitatively assess quality of feedback display. However, currently, we see this tool as a way to help developers reflect on their A\&F interventions and consider whether they may be able to improve their A\&F. We hope to continue to streamline and iteratively improve this tool over time, by working to incorporate new findings and guidance for A\&F development.

\section{Conclusions}

We developed a theory-informed 52-item tool for assessing the degree of concordance of A\&F interventions with best practice recommendations and applied it to A\&F in critical care. Within critical care, only two items were adhered to by all studies. Our evaluation tool provides a potential way forward to help improve reporting of A\&F interventions, for assessing their concordance with agreed best practice and to inform the development of improved A\&F interventions.

\section{Abbreviations}

A\&F: Audit and feedback; ICU: Intensive care unit

\section{Supplementary Information}

The online version contains supplementary material available at https://doi. org/10.1186/s13012-021-01145-9.

Additional File 1. Consolidated criteria for reporting qualitative studies (COREQ) checklist.

Additional File 2. Cohen's Kappa Calculation.

Additional File 3. Full evaluation tool, including response scales and anchors.

Additional File 4. PRISMA flow diagram of the study selection. 
Additional File 5. Assessment of remaining descriptive items.

\section{Acknowledgements}

The authors would like to thank the authors of each respective article who provided additional information and materials.

\section{Authors' contributions}

JCB and JP were responsible for the conception of this project and provided guidance and expertise throughout the entire project. All members of the study team were involved in the development of the evaluation tool (JCB, JP, MF, MP). MF and MP piloted the evaluation tool. Formal assessment of the identified studies was completed by MF and confirmed by EP. JCB and JP provided guidance throughout the consensus phases. MF drafted the manuscript and JCB, JP, LM, EP, and MP provided critical input and aided in the revision of the manuscript. All authors have read and approved the final manuscript. The guarantor of this report is MF.

\section{Funding}

MF received a Queen Elizabeth II scholarship for her Master's thesis, MF also received a University of Ottawa Graduate Studies Scholarship, and held a graduate studentship with the Ottawa Hospital Research Institute. This work was also supported by a Canadian Institutes of Health Research (CIHR) grant (Funding Reference Number: PJT156031). Funding bodies had no role in the design of the study, collection, analysis, interpretation of data, or in the writing of the manuscript.

\section{Availability of data and materials}

The datasets used and/or analyzed during the current study are available from the corresponding author on reasonable request; however, the data and materials pertaining to individual participants will not be shared to protect privacy. Coding tools are also available from authors upon request.

\section{Declarations}

\section{Ethics approval and consent to participate}

This study was approved by the Ottawa Health Science Network Research Ethics Board (OHSN-REB; Protocol ID: 20160951-01H). The corresponding authors of studies identified through systematic review were contacted to request the sharing of feedback forms. Individuals were informed that by sharing these study materials they were providing consent to participate in the study.

\section{Consent for publication}

Not applicable.

\section{Competing interests}

The authors declare that they have no competing interests.

\section{Author details}

${ }^{1}$ School of Epidemiology and Public Health, University of Ottawa, 451 Smyth Road, Ottawa, ON K1H 8M5, Canada. ${ }^{2}$ Ottawa Hospital Research Institute, Clinical Epidemiology Program, The Ottawa Hospital, General Campus, 501 Smyth Road, Centre for Practice Changing Research, Box 201B, Ottawa, ON K1H 8L6, Canada. ${ }^{3}$ School of Psychology, University of Ottawa, 136 Jean-Jacques Lussier, Vanier Hall, Ottawa, ON K1N 6N5, Canada. ${ }^{4}$ Department of Critical Care Medicine, The Ottawa Hospital, General Campus, 501 Smyth Road, Ottawa, ON K1H 8L6, Canada.

\section{Received: 11 January 2021 Accepted: 24 July 2021}

\section{Published online: 17 August 2021}

\section{References}

1. Ivers N, Jamtvedt G, Flottorp S, Young JM, Odgaard-Jensen J, French SD, et al. Audit and feedback: effects on professional practice and healthcare outcomes (Review). Cochrane Database Syst Rev. 2012;6:1-227 Available from: http://www.ncbi.nlm.nih.gov/pubmed/22696318.

2. Ivers NM, Grimshaw JM, Jamtvedt G, Flottorp S, O'Brien MA, French SD, et al. Growing Literature, Stagnant Science? Systematic Review, MetaRegression and Cumulative Analysis of Audit and Feedback Interventions in
Health Care. J Gen Intern Med. 2014;29(11):1534-41. https://doi.org/10.1007/ s11606-014-2913-y.

3. Ivers NM, Grimshaw JM. Reducing research waste with implementation laboratories. Lancet. 2016;388(10044):547-8. Available from:. https://doi.org/1 0.1016/S0140-6736(16)31256-9.

4. Brehaut JC, Colquhoun HL, Eva KW, Carroll K, Sales A, Michie S, et al. Practice feedback interventions: 15 suggestions for optimizing effectiveness. Ann Intern Med. 2016;164(6):435-41. https://doi.org/10.7326/M15-2248.

5. Gude WT, Roos-Blom MJ, van der Veer SN, de Jonge E, Peek N, Dongelmans DA, et al. Electronic audit and feedback intervention with action implementation toolbox to improve pain management in intensive care: Protocol for a laboratory experiment and cluster randomised trial. Implement Sci. 2017;12(1):68. https://doi.org/10.1186/s13012-017-0594-8.

6. Donchin Y, Seagull FJ. The hostile environment of the intensive care unit. Curr Opin Crit Care. 2002;8(4):316-20. https://doi.org/10.1097/00075198-2002 08000-00008.

7. Bjurling-Sjöberg P, Wadensten B, Pöder U, Jansson I, Nordgren L. Balancing intertwined responsibilities: a grounded theory study of teamwork in everyday intensive care unit practice. J Interprof Care. 2017;31(2):233-44 Available from: https://www.tandfonline.com/doi/full/10.1080/13561820.201 6.1255184 .

8. Scales DC, Sibbald WJ. Medical technology in the intensive care unit. Curr Opin Crit Care. 2004;10(4):238-45 Available from: /Users/EWN/Documents/ Arkiv_artikler/5100_5199/5174_med_techn_ICU.pdf.

9. Boev C. The relationship between nurses' perception of work environment and patient satisfaction in adult critical care. J Nurs Scholarsh. 2012;44(4): 368-75. https://doi.org/10.1111/j.1547-5069.2012.01466.x.

10. Alameddine M, Dainty KN, Deber R, Sibbald WJ(B). The intensive care unit work environment: current challenges and recommendations for the future. J Crit Care. 2009;24(2):243-8. Available from:. https://doi.org/10.1016/j.jcrc.2 008.03.038.

11. Adhikari N, Lapinsky SE. Medical informatics in the intensive care unit: Overview of Technology Assessment. J Crit Care. 2003;18(1):41-7. https:// doi.org/10.1053/jcrc.2003.YJCRC9.

12. Nilsen P, Roback K, Broström A, Ellstrøm P-E. Creatures of habit: accounting for the role of habit in implementation research on clinical behavior change. Implement Sci. 2012;7(1):53. https://doi.org/10.1186/1 748-5908-7-53.

13. Merkeley HL, Hemmett J, Cessford TA, Amiri N, Geller GS, Baradaran N, et al. Multipronged strategy to reduce routine-priority blood testing in intensive care unit patients. J Crit Care. 2016;31(1):212-6. Available from:. https://doi. org/10.1016/j.jcrc.2015.09.013

14. Kotecha N, Shapiro JM, Cardasis J, Narayanswami G. Reducing Unnecessary Laboratory Testing in the Medical ICU. Am J Med. 2017:130(6):648-51. Available from:. https://doi.org/10.1016/j.amjmed.2017.02.014.

15. Raad S, Elliott R, Dickerson E, Khan B, Diab K. Reduction of laboratory utilization in the intensive care unit. J Intensive Care Med. 2016; 0885066616651806 Available from: http://jic.sagepub.com/cgi/doi/10.1177/ 0885066616651806.

16. Ezzie ME, Aberegg SK, O'Brien JM. Laboratory testing in the intensive care unit. Crit Care Clin. 2007;23(3):435-65. https:/doi.org/10.1016/j.ccc.2007.07.005.

17. Cismondi F, Celi LA, Fialho AS, Vieira SM, Reti SR, Sousa JMC, et al. Reducing unnecessary lab testing in the ICU with artificial intelligence. Int J Med Inform. 2013;82(5):345-58. Available from:. https://doi.org/10.1016/j. ijmedinf.2012.11.017.

18. McEvoy MT, Shander A. Anemia, bleeding, and blood transfusion in the intensive care unit: causes, risks, costs, and new strategies. Am J Crit Care. 2013;22(6 Suppl):eS1-13.

19. Carson JL, Stanworth SJ, Roubinian N, Fergusson DA, Triulzi D, Doree C, et al. Transfusion thresholds and other strategies for guiding allogeneic red blood cell transfusion (Review). Cochrane Database Syst Rev. 2016;(10):1118 Available from: http://www.pubmedcentral.nih.gov/articlerender.fcgi?a rtid $=4171966 \&$ tool $=$ pmcentrez\&rendertype $=$ abstract.

20. Marik PE, Corwin HL. Efficacy of red blood cell transfusion in the critically ill: a systematic review of the literature. Crit Care Med. 2008;36(9):2667-74. Available from: http://content.wkhealth.com/linkback/openurl?sid=WKPTLP: landingpage\&an=00003246-200809000-00026\%5Cnhttp://www.ncbi.nlm.nih. gov/pubmed/18679112. https://doi.org/10.1097/CCM.0b013e3181844677.

21. Alport EC, Callum JL, Nahirniak S, Eurich B, Hume HA. Cryoprecipitate use in 25 Canadian hospitals: commonly used outside of the published guidelines. Transfusion. 2008;48(10):2122-7. https://doi.org/10.1111/j.1537-2995.2008.01826.x. 
22. Etchells M, Spradbrow J, Cohen R, Lin Y, Armali C, Lieberman L. Audit of appropriate use of platelet transfusions: validation of adjudication criteria. Vox Sang. 2018;113(1):40-50. https://doi.org/10.1111/vox.12550.

23. Tinmouth A, Thompson T, Arnold DM, Callum JL, Gagliardi K, Lauzon D, et al. Utilization of frozen plasma in Ontario: a provincewide audit reveals a high rate of inappropriate transfusions. Transfusion. 2013;53(10):2222-9. https://doi.org/10.1111/trf.12231.

24. Murphy MF, Goodnough LT. The scientific basis for patient blood management. Transfus Clin Biol. 2015;22(3):90-6. Available from:. https://doi. org/10.1016/j.tracli.2015.04.001.

25. Zhu C, Gao Y, Li Z, Li Q, Gao Z, Liao Y, et al. A systematic review and metaanalysis of the clinical appropriateness of blood transfusion in China. Med. 2015;94(50):e2164 Available from: http://content.wkhealth.com/linkback/ openurl?sid=WKPTLP:landingpage\&an=00005792-201512150-00020.

26. Foster M, Presseau J, McCleary N, Carroll K, McIntyre L, Hutton B, et al. Audit and feedback to improve laboratory test and transfusion ordering in critical care: a systematic review. Implement Sci. 2020;15(1):46. https://doi.org/10.11 86/s13012-020-00981-5.

27. Tong A, Sainsbury P, Craig J. Consolidated criteria for reporting qualitative research (COREQ): A 32-item checklist for interviews and focus groups. Int J Qual Health Care. 2007;19(6):349-57. https://doi.org/10.1093/intahc/ mzm042.

28. Hallgren KA. Computing inter-rater reliability for observational data: an overview and tutorial. Tutor Quant Methods Psychol. 2012;8(1):23-34. Available from: http://www.tqmp.org/RegularArticles/vol08-1/p023. https:// doi.org/10.20982/tgmp.08.1.p023.

29. Merlani P, Garnerin P, Diby M, Ferring M, Ricou B. Quality improvement report: linking guideline to regular feedback to increase appropriate requests for clinical tests: blood gas analysis in intensive care. BMJ. 2001; 323(7313):620-4. Available from: http://www.pubmedcentral.nih.gov/a rticlerender.fcgi?artid=1121188\&tool=pmcentrez\&rendertype=abstract. https://doi.org/10.1136/bmj.323.7313.620.

30. Beland D, D'Angelo C, Vinci D. Reducing unnecessary blood work in the neurosurgical ICU. J Neurosci Nurs. 2003;35(3):149-52. Available from: http://sea rch.ebscohost.com/login.aspx?direct=true \&db=cin20\&AN=106867699\&site= ehost-live. https://doi.org/10.1097/01376517-200306000-00004.

31. Hendryx MS, Fieselmann JF, Bock MJ, Wakefield DS, Helms CM, Bentler SE. Outreach education to improve quality of rural ICU care: results of a randomized trial. Am J Respir Crit Care Med. 1998;158(2):418-23. https://doi. org/10.1164/ajrccm.158.2.9608068.

32. Paes BA, Modi A, Dunmore R. Changing physicians' behavior using combined strategies and an evidence-based protocol. Arch Pediatr Adolesc Med. 1994;148(12):1277-80. Available from: http://ovidsp.ovid.com/ovidweb. cgi?T=JS\&PAGE=reference\&D=med3\&NEWS=N\&AN=7951806. https://doi. org/10.1001/archpedi.1994.02170120039006

33. Wisser D, Van Ackern $K$, Knoll E, Wisser $H$, Bertsch T. Blood loss from laboratory tests. Clin Chem. 2003;49(10):1651-5. https://doi.org/10.1373/49.1 0.1651.

34. Diby M, Merlani P, Garnerin P, Ricou B. Harmonization of practice among different groups of caregivers: a guideline on arterial blood gas utilization. J Nurs Care Qual. 2005;20(4):327-34. Available from: http://search.ebscohost. com/login.aspx?direct=true\&db=cin20\&AN=106540547\&site=ehost-live. https://doi.org/10.1097/00001786-200510000-00008.

35. Calderon-Margalit R, Mor-Yosef S, Mayer M, Adler B, Shapira SC. An administrative intervention to improve the utilization of laboratory tests within a university hospital. Int J Qual Health Care. 2005;17(3):243-8. https:// doi.org/10.1093/intqhc/mzi025.

36. Petäjä J, Andersson S, Syrjälä M. A simple automatized audit system for following and managing practices of platelet and plasma transfusions in a neonatal intensive care unit. Transfus Med. 2004;14(4):281-8. https://doi. org/10.1111/j.0958-7578.2004.00515.x.

37. Gutsche JT, Kornfield ZN, Speck RM, Patel PA, Atluri P, Augoustides JG. Impact of guideline implementation on transfusion practices in a surgical intensive care unit. J Cardiothorac Vasc Anesth. 2013;27(6):1189-93. https:// doi.org/10.1053/j.jvca.2013.05.040.

38. Yeh DD, Naraghi L, Larentzakis A, Nielsen N, Dzik W, Bittner EA, et al. Peerto-peer physician feedback improves adherence to blood transfusion guidelines in the surgical intensive care unit. J Trauma Acute Care Surg. 2015;79(1):65-70. Available from: http://www.scopus.com/inward/record. url?eid=2-s2.0-84935080098\&partnerlD=tZOtx3y1. https://doi.org/10.1097/TA. 0000000000000683.
39. Borgert M, Binnekade J, Paulus F, Goossens A, Vroom M, Dongelmans D. Timely individual audit and feedback significantly improves transfusion bundle compliance_a comparative study. Int J Qual Health Care. 2016;28(5):601-7. Available from: http://ovidsp.ovid.com/ovidweb.cgi?T=JS\&PAGE=reference\&D= medp\&NEWS=N\&AN=27424329. https://doi.org/10.1093/intqhc/mzw071.

40. Masud F, Larson-Pollock K, Leveque C, Vykoukal D. Establishing a culture of blood management through education: a quality initiative study of postoperative blood use in CABG Patients at Methodist DeBakey Heart \& Vascular Center. Am J Med Qual. 2011;26(5):349-56. Available from: http://search.ebscohost.com/login.aspx?direct=true\&db= cin20\&AN=104577658\&site=ehost-live. https://doi.org/10.1177/1062 860611398532.

41. Beaty CA, Haggerty KA, Moser MG, George TJ, Robinson CW, Arnaoutakis GJ, et al. Disclosure of physician-specific behavior improves blood utilization protocol adherence in cardiac surgery. Ann Thorac Surg. 2013;96(6):2168-74 Available from:. https://doi.org/10.1016/j.athoracsur.2013.06.080.

42. Arnold DM, Lauzier F, Whittingham H, Zhou Q, Crowther MA, McDonald E, et al. A multifaceted strategy to reduce inappropriate use of frozen plasma transfusions in the intensive care unit. J Crit Care. 2011;26(6):636.e7-636.e13. Available from:. https://doi.org/10.1016/j.jcrc.2011.02.005.

43. Solomon RR, Clifford JS, Gutman SI. The use of laboratory intervention to stem the flow of fresh-frozen plasma. Am J Clin Pathol. 1988;89(4):518-21. https://doi.org/10.1093/ajcp/89.4.518.

44. Murphy DJ, Lyu PF, Gregg SR, Martin GS, Hockenberry JM, Coopersmith CM, et al. Using incentives to improve resource utilization: a quazi-experimental evaluation of an ICU quality improvement program. Crit Care Med. 2016; 44(1):162-70. Available from: http://search.ebscohost.com/login.aspx?direct= true\&db=cin20\&AN=111797832\&site=ehost-live. https://doi.org/10.1097/ CCM.0000000000001395

45. Schramm GE, Kashyap R, Mullon JJ, Gajic O, Afessa B. Septic shock: a multidisciplinary response team and weekly feedback to clinicians improve the process of care and mortality. Crit Care Med. 2011;39(2):252-8. Available from: http://content.wkhealth.com/linkback/openurl?sid=WKPTLP: landingpage\&an=00003246-201102000-00002\%5Cnhttp://www.ncbi.nlm.nih gov/pubmed/21057312. https://doi.org/10.1097/CCM.0b013e3181ffde08.

46. Eccles M, Grimshaw J, Walker A, Johnston M, Pitts N. Changing the behavior of healthcare professionals: the use of theory in promoting the uptake of research findings. J Clin Epidemiol. 2005;58(2):107-12. https://doi.org/10.101 6/j.jclinepi.2004.09.002.

47. Craig P, Dieppe P, Macintyre S, Mitchie S, Nazareth I, Petticrew M. Developing and evaluating complex interventions: the new Medical Research Council guidance. BMJ. 2008;337(a1655).

48. Colquhoun HL, Brehaut JC, Sales A, Ivers N, Grimshaw J, Michie S, et al. A systematic review of the use of theory in randomized controlled trials of audit and feedback. Implement Sci. 2013;8:66 Available from: http://www. pubmedcentral.nih.gov/articlerender.fcgi?artid=3702512\&tool= pmcentrez\&rendertype $=$ abstract.

49. Atkins L, Francis J, Islam R, O'Connor D, Patey A, Ivers N, et al. A guide to using the theoretical domains framework of behaviour change to investigate implementation problems. Implement Sci. 2017;12(1):77 Available from: http://implementationscience.biomedcentral.com/articles/1 0.1186/s13012-017-0605-9.

50. Grol RP, Bosch MC, Hulscher ME, Eccles M, Wensing M. Planning and studying improvement in patient care: the use of theoretical perspectives. Milbank Q. 2007:85(1):93-138. https://doi.org/10.1111/j.1468-0009.2007.00478.x.

51. Davies P, Walker A, Grimshaw J. A systematic review of the use of theory in the design of guideline dissemination and implementation strategies and interpretation of the results of rigorous evaluations. Implement Sci. 2010; 5(1):14. https://doi.org/10.1186/1748-5908-5-14.

52. French SD, Green SE, O'Connor DA, McKenzie JE, Francis JJ, Michie S, et al. Developing theory-informed behaviour change interventions to implement evidence into practice: a systematic approach using the Theoretical Domains Framework. Implement Sci. 2012;7(1):38 Available from: http:// www.implementationscience.com/content/7/1/38.

53. Birken SA, Powell BJ, Shea CM, Haines ER, Alexis Kirk M, Leeman J, et al. Criteria for selecting implementation science theories and frameworks: results from an international survey. Implement Sci. 2017;12(1):124 Available from: http:// implementationscience.biomedcentral.com/articles/10.1186/s13012-017-0656-y.

54. Birken SA, Rohweder CL, Powell BJ, Shea CM, Scott J, Leeman J, et al. TCaST: an implementation theory comparison and selection tool. Implement Sci. 2018;13(1):143. https://doi.org/10.1186/s13012-018-0836-4. 
55. Davis DA, Mazmanian PE, Fordis M, Van HR, Thorpe KE, Perrier L. Accuracy of physician self-assessment compared with observed measures of competence. JAMA. 2006;296(9):1094-102. https://doi.org/10.1001/jama.296. 9.1094.

56. Hysong ST. Meta-analysis: audit and feedback features impact effectiveness on care quality. Med Care. 2009;47(3):356-63. https://doi.org/10.1097/MLR. 0b013e3181893f6b.

57. Sinuff T, Muscedere J, Rozmovits L, Dale CM, Scales DC. A qualitative study of the variable effects of audit and feedback in the ICU. BMJ Qual Saf. 2015; 24(6):393-9 Available from: http://qualitysafety.bmj.com/lookup/doi/10.1136/ bmjas-2015-003978.

58. Webster F, Patel J, Rice K, Baxter N, Paszat L, Rabeneck L, et al. How to Make Feedback More Effective? Qualitative Findings from Pilot Testing of an Audit and Feedback Report for Endoscopists. Can J Gastroenterol Hepatol. 2016; 2016:4983790.

59. Potthoff S, Presseau J, Sniehotta FF, Johnston M, Elovainio M, Avery L. Planning to be routine : habit as a mediator of the planning-behaviour relationship in healthcare professionals. Implement Sci. 2017;12(1):24. https://doi.org/10.1186/s13012-017-0551-6.

60. Colquhoun H, Michie S, Sales A, Ivers N, Grimshaw JM, Carroll K, et al. Reporting and design elements of audit and feedback interventions: a secondary review [published online Jan 25 2016]. BMJ Qual Saf. 2016; Available from: http://www.ncbi.nlm.nih.gov/pubmed/26811541.

61. DeVon HA, Block ME, Moyle-Wright P, Ernst DM, Hayden SJ, Lazzara DJ, et al. A psychometric toolbox for testing validity and reliability. J Nurs Scholarsh. 2007;39(2):155-64. https://doi.org/10.1111/j.1547-5069.2007.00161.X.

\section{Publisher's Note}

Springer Nature remains neutral with regard to jurisdictional claims in published maps and institutional affiliations.

Ready to submit your research? Choose BMC and benefit from:

- fast, convenient online submission

- thorough peer review by experienced researchers in your field

- rapid publication on acceptance

- support for research data, including large and complex data types

- gold Open Access which fosters wider collaboration and increased citations

- maximum visibility for your research: over $100 \mathrm{M}$ website views per year

At BMC, research is always in progress.

Learn more biomedcentral.com/submissions 